\title{
Study on the Dynamic Mechanism of College Student Organization
}

\author{
Yinghan Lv \\ International Business School, Jinan University, Zhuhai, China \\ Email: 547460313@qq.com
}

How to cite this paper: Lv, Y.H. (2018) Study on the Dynamic Mechanism of College Student Organization. Open Journal of Social Sciences, 6, 158-164.

https://doi.org/10.4236/jss.2018.612014

Received: December 7, 2018

Accepted: December 25, 2018

Published: December 28, 2018

Copyright $\odot 2018$ by author and Scientific Research Publishing Inc. This work is licensed under the Creative Commons Attribution International License (CC BY 4.0).

http://creativecommons.org/licenses/by/4.0/

\begin{abstract}
College student organization plays an important role in the management of college. A college in Chengdu has become a hot topic on weibo because of a screenshot of a dialogue with strong bureaucratic color recently, which have attracted wide attention of the society. The management problem of college student organization keeps showing up. How to keep the initiative and advancement of college student organization has become an important subject in college research. Based on the analysis of the current situation of college student organization, this paper explores the dynamic mechanism of college student organization, and puts forward feasible suggestions on the management of college student organization.
\end{abstract}

\section{Keywords}

College, Student Organization, Dynamic Mechanism

\section{Current Situation and Problem Analysis of College Student Organization}

The college student organizations are composed by students in the college campus, including the student union, student association federation, student association, student classes and so on. The organizations of college are different from the organizations of primary education. The organizations of college have stronger autonomy. In primary education, teachers still occupy the dominant position in student organizations, and the autonomy of student organizations is limited, so they are not within the scope of this paper. With the advent of the popularization era of higher education, higher education pays more and more attention to the connotative development. In the process of improving the quality of education and cultivating high-quality talents with all-round development, the important role of college student organization is prominent increasingly. 
However, at present, there are so many problems of student organizations, such as the lack of the main body status, low work efficiency, the widespread phenomenon of management by administrative orders and subjective experience [1] [2], the emergence of bureaucratic style, the weakening of enthusiasm for student work and so on. Students lose the trust and support for student organizations gradually.

The root of the problem is from the internal management, such as, the work objectives of student cadres are blurry, the work performance evaluation system is incomplete, and lack the propulsion of continuous motivation. Pursuing their own selves, lacking sense of responsibility and other characteristics of the times lead to the current problems of college student organization as well. How to promote the benign development of college student organization and explore the dynamic mechanism of college student organization becomes the focus of this paper.

\section{The Dynamic Mechanism of College Student Organization}

The mechanism is the coupling relationship and mechanism of action between elements. Motivation refers to various factors that urge, promote and motivate the developer to move to the set goal [3]. Dynamic mechanism, that is, under the dynamic support, the coupling between the elements and the mechanism of action. The dynamic mechanism of student organization is the process of establishing effective guidance, motivation, restraint and control mechanism through the interaction of rights, responsibilities and interest subjects in the student organization. The theory of dynamic mechanism is based on human nature. The organization order is constructed to make the organization become an organism with self-generating ability through "mechanism".

\subsection{The Guide Mechanism of College Student Organization}

The guiding mechanism is to induce people's behavior through the appearance of people's "speech", according to the motivation that governs "behavior", and establish the corresponding system based on cultural factors to guide the direction of enthusiasm [4]. Dawkins believes that various self-interested strategies must be adopted if genes are to continue in the competition for survival [5]. Thus, the genes screened by nature's law of selection should be self-interested. Based on such human nature hypothesis, in order to give full play to the subjective initiative of members of student organizations, it is necessary to satisfy individual needs as the premise, to promote individuals to generate behavioral motivation and derive behaviors, so as to achieve organizational goals actively and form the guiding mechanism of college student organizations, as shown in Figure 1.

It can motivate people's initiative and subjective initiative by designing the dynamic mechanism around people's instinct to pursue interests. And it provides the source power for organization development [4]. In this process, the 


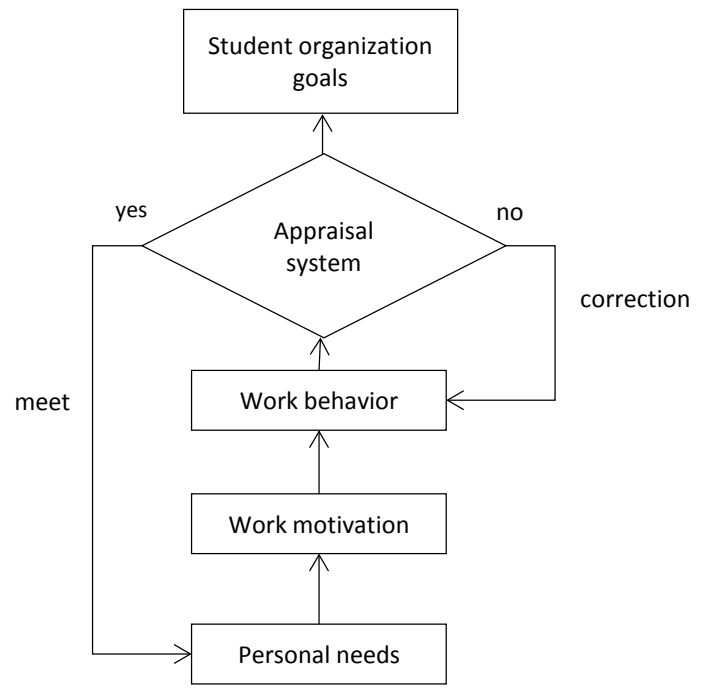

Figure 1. The guiding mechanism of college student organization.

key is to integrate personal interests with organizational interests, and lead people's enthusiasm to the track of realizing organizational goals.

Look for alignment between personal and organizational goals. Warren Bennis believes that an organization is a complex social unit that pursues its own goals. Its members should adapt to the organizational goals and the organizational goals should adapt to individual goals as well [4]. The key to realize the guidance mechanism is to find the joint point between individual goal and organization goal. The reason why individuals join organizations is that organizations can meet their needs. But different individuals have different levels of needs. Maslow's hierarchy of needs theory divides individual needs into five levels: physiological needs, safety needs, communication needs, respect needs and self-actualization needs. The administrators of student organizations should pay full attention to the needs of different levels of individuals, combine the characteristics of different levels of needs, and combine personal needs with organizational goals organically. When there is a short conflict between individual interests and organizational interests, the incentive mechanism and constraint mechanism are used to attract individual interests to the joint point consistent with organizational interests.

Establish a fair and equitable evaluation system to achieve the transformation of individual goals and organizational goals. There are no systematic evaluation system with fair procedure and no specific quantitative evaluation index in most of student organizations. Assessment in organization is the only way to translate individuals' behaviors into actual rewards, which include internal rewards and external rewards. In addition to material rewards, members of student organizations pay more attention to intrinsic rewards, such as the sense of achievement and value. On the one hand, the interests of individuals and the degree of satisfaction of personal needs are determined by the assessment results. On the other 
hand, the assessment results prompt individuals to adjust their goals constantly in order to meet the criteria of the assessment indicators.

\subsection{The Incentive Mechanism of College Student Organizations}

Berelson and Steiner defined motivation as all the conditions, hopes, desires and motivations that the heart wants to strive for, and it is an inner state of human activities [6]. Incentive mechanism refers to the way in which the incentive subject interacts with the incentive object through incentive factors or means in the organizational system [7]. There is a lack of sustainable power source in the college student organizations, and it is driven by the continuing pursuit of individual goals and organization goals for the members of the student organization. On the one hand, the influencing factors come from the ambiguity of organizational goals and the separation between individual goals and organizational goals. On the other hand, it comes from the lack of practical and targeted incentive mechanism.

Combined the intrinsic motivation with extrinsic motivation, and to construct multiple motivation mechanism in college student organization. The combination of inner and outer can maintain the sustained motivation of students' work at the organization. Intrinsic motivation mainly refers to the satisfaction and sense of achievement that the student brought from the work. Extrinsic motivation mainly refers to rewards and incentives outside the work, including the titles of outstanding cadres, student cadre scholarships and so on. According to the needs of different levels of individuals, different incentive policies are given to meet the increasingly rich individual needs of the members of student organizations through diversified incentive policies.

\subsection{The Constraint Mechanism of College Student Organization}

Leonardo Da Vinci once said that "power is born in restraint and dies in freedom", and restraint is a necessary condition for the generation of power. Constraint mechanism is to regulate human behavior through a series of rules and regulations, to restrict behaviors which are contrary to the organizational goals, to integrate the drive of organization members and cluster together, to avoid the loss of energy, and form stronger motivation [4]. At present, student organizations in colleges are reported continuously that the organization management is chaotic and the bureaucratic style is obvious. These are the sign that the organizational constraint mechanism is not sound.

Combined the self-discipline with heteronomy. Self-discipline is the internal self-restraint of an individual. It restrains individual behaviors through individual consciousness and enables people to act within the scope of work responsibilities consciously and voluntarily. However, from the perspective that the people are self-interested, self-discipline is not a solid defense line and cannot guarantee the purity within the organization. In addition, we should also attach importance to other constraints such as organizational rules and regulations, and build a constraint mechanism system of internal and external. 
Through the restriction coupling between the members of the student organization, the interests are balanced. He who gains the benefit, enjoys the right, and also should assume the responsibility. If the power and interests of the members of the organization are not standardized, it is easy to lead to abuse of power. Student organizations are generally divided into three levels: secretary, minister and bureau. The latter level arranges and directs the work of the former level. The restriction coupling between members of student organization can be realized by vertical and horizontal constraint. Vertical constraint restrains the behavior of members of student organizations through mutual evaluation of work performance between two adjacent levels. Horizontal constraint strengthens internal communication of the organization through mutual evaluation of work performance at the same level. In order to avoid the unfair phenomenon of favoritism and fraud, it can be achieved by the optimized of the evaluation system, as shown in Figure 2.

\subsection{The Control Mechanism of College Student Organization}

Control is a strategic and active behavior that the controller chooses appropriate means to act on the controlled object so as to cause the expected change of the controlled person's behavior. The student organization is a collection of individuals with different goals, abilities and personalities. In order to ensure the efficient operation of the organization, it is particularly important to control the members of the organization. The control mechanism is different from the constraint mechanism. The constraint mechanism is static, real-time and regular constraint, but the control mechanism is dynamic, temporal and exceptional. Constraint mechanism restricts behaviors according to organizational rules and regulations, while control mechanism relies on control results which are planned [4].

Grasp the key points of control and construct efficient control mechanism. College student organizations engaged in student activities is a continuous process. It is a high cost to achieve full control on organization members and the efficiency is low. Thus, seize the key control points in the process, give students members greater autonomy, stimulate the innovation and creativity of the organization members, grasp the development direction of student organization, and bring order out of chaos right on time.

\section{Summary and Outlook}

From the perspective of dynamic mechanism, this paper explores the deficiencies of college student organization in the construction of dynamic mechanism system. Through the four dimensions of guidance mechanism, incentive mechanism, constraint mechanism and control mechanism, this paper analyzes the problems existing in the management of college student organization and forms the dynamic mechanism of college student organization (as shown in Figure 3). This paper provides directional guidance for the further improvement of college student organization system. 


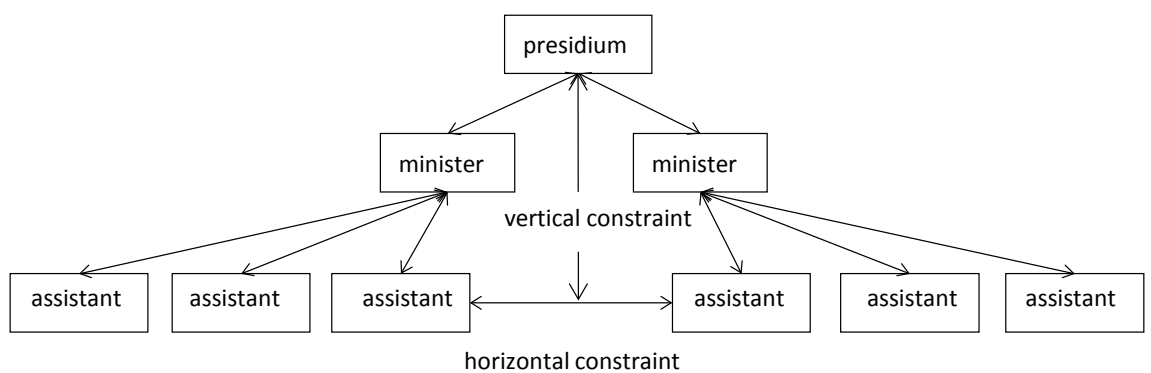

Figure 2. The constraint mechanism of college student organization.

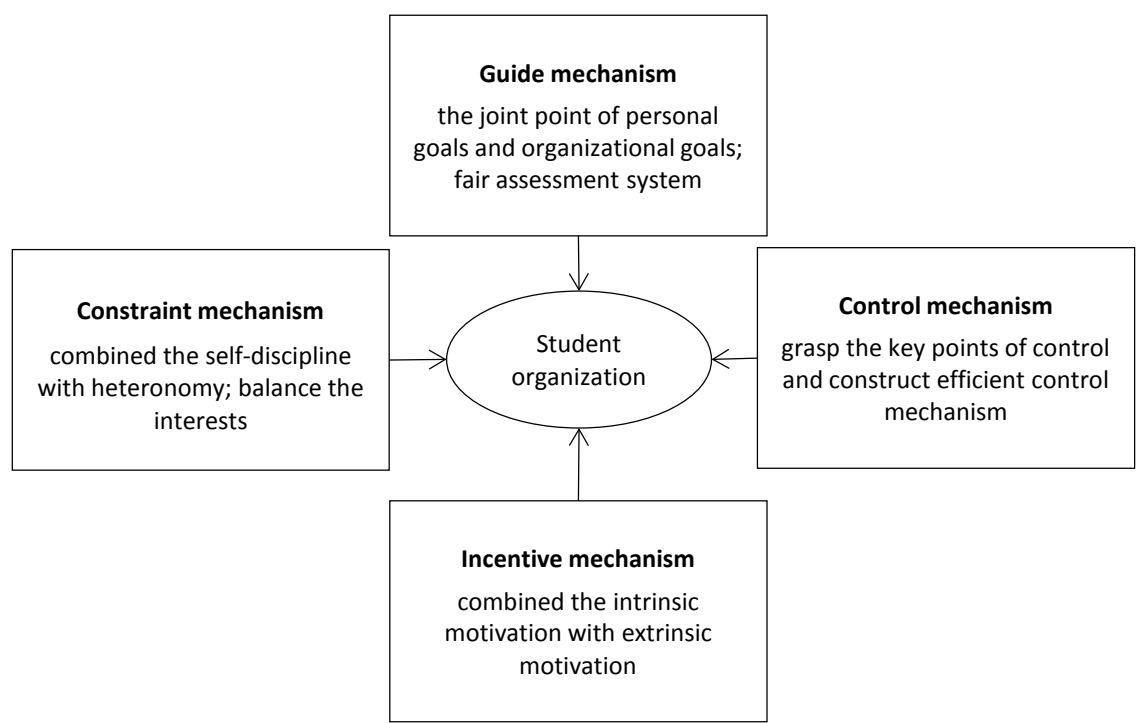

Figure 3. Dynamic Mechanism of college student organization.

In the management of college student organization, this paper suggests that the college student organization should satisfy the need of personal development of the college student organization to find the joint point of personal goals and organizational goals, and establish a fair assessment system to achieve the effective transformation of individual goals and organizational goals; combined the intrinsic motivation with extrinsic motivation to construct multiple motivation mechanism in college student organization; combined the self-discipline with heteronomy, and through the restriction coupling between the members of the student organization to achieve the interests balanced; Grasp the key points of control and construct efficient control mechanism. Through the guidance, incentive, restraint and control mechanism, individuals can be guided actively, and individual strength can be combined into the joint force to pursue the achievement of organizational goals, so as to achieve the mutually-beneficial coexistence between individuals and organizations.

\section{Conflicts of Interest}

The authors declare no conflicts of interest regarding the publication of this paper. 


\section{References}

[1] Su, Y.R. (2015) Analysis on the Development of College Student Organization. EXploration of Higher Education, No. 5, 117-120.

[2] Wang, F. (2014) Scientific Research on Student Organization and Management in Colleges and Universities. Nanjing Normal University, Nanjing.

[3] Yang, X.R. (2010) Study on the Dynamic Mechanism of Human Resource Development. Human Resource Development in China, No. 5, 92-96.

[4] Hao, Y.Q. (2010) The Dynamic Mechanism of Organizational Management. Economic Science Press, Beijing.

[5] Dawkins, R., Lu, Y.Z. and Zhang, D.Y. (1981) Selfish Genes. Science Press, Beijing.

[6] Berelson, B. and Steiner, G.A. (1964) Human Behavior: An Inventory of Scientific Findings. Harcourt Brace Jovanovich, New York, 239.

[7] Chen, C. (2018) Research on Employee Motivation Mechanism of Service Industry Based on Grounded Theory: A Case Study of Haidilao. Jinan University, Guangzhou. 